\title{
Variables correlated with elderly referral from nursing homes to general hospitals
}

\author{
Shir Wagman', Shmuel Rishpon ${ }^{2,3}$, Genady Kagan², Jonathan Dubnov 2,3 and Sonia Habib ${ }^{2,3^{*}}$
}

\begin{abstract}
Background: Referring patients from nursing homes to general hospitals exposes them to nosocomial diseases, and may result in the development of a broad spectrum of physical, mental and social damages. Therefore, minimizing the referring of nursing home patients to hospitals is an important factor for keeping the elderly healthy and minimizing health expenditures. In this study we examined the variables related to the referral rates from nursing homes to general hospitals and the relationship between the referral and the mortality rates among the elderly who live in nursing homes in the Haifa Sub-district.

Methods: Thirty-two nursing homes were included in a cross-sectional study. All medical directors and head nurses were interviewed using a structured questionnaire between November 2006 and October 2007. Statistical analysis, including the ANOVA and the nonparametric Spearman tests, were employed to determine the factors that influence referral rates and the correlation between referral rates and mortality rates.

Results: The referral rate ranged between 18 and 222 per 100 financed elderly in a single year. In the multivariate analysis, the absence of a physician from the nursing home at the time of the referral to general hospitals was the only significant variable related to referral rates. No significant relationships were found between referral rates and mortality rates.

Conclusions: Absence of a significant relationship between referral rates and mortality rates may indicate that high referral rates do not necessarily protect the elderly from death. Therefore, any recommendations issued by the Ministry of Health $(\mathrm{MOH})$ should emphasize in-house treatment rather than hospitalization. Clear instructions on referral from nursing homes to general hospitals need to be constructed by the $\mathrm{MOH}$. The $\mathrm{MOH}$ should increase the presence of physicians in the nursing homes, especially, when the need to refer a patient arises. Further quantitative and epidemiologic studies should be conducted in order to, more fully and reliably, create guidelines for policy recommendations.
\end{abstract}

Keywords: Elderly, Hospitalization, Nursing homes, Referral rates

\section{Background}

Nursing homes (NHs) are characterized by nursing and supportive treatment for elderly patients suffering from cognitive disorders and patients who need constant, prolonged attention and care [1]. While general hospitals are characterized by medical expertise and medical technologies, there is minimal focus on prolonged treatment. In hospitals, the level of nursing and patient care for the

\footnotetext{
* Correspondence: sonia.habib@lbhaifa.health.gov.il

${ }^{2}$ Haifa District Health Office, Ministry of Health, Haifa, Israel

${ }^{3}$ Faculty of Welfare and Health Sciences, School of Public Health, University of Haifa, Haifa, Israel

Full list of author information is available at the end of the article
}

elderly is lower than it is in NHs. The referral of patients from NHs to general hospitals often exposes them to iatrogenic diseases and can result in psychological and social damage [2]. Thus, minimizing hospitalizations is important for keeping the elderly healthy as well as for limiting costs [2]. Socio-demographic characteristics, health characteristics, nursing staff related characteristics and the availability of other services are variables that affect the referring of elderly patients to general hospitals [3]. Hospitalization in a general hospital causes a decline in the nutritional status of the patient and additional, often infectious, complications. Among patients suffering from malnutrition, higher rates of repeated hospitalizations and higher mortality rates

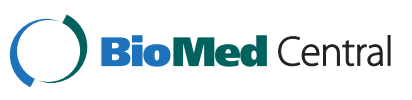


were observed. For elderly patients, hospitalization in itself is a factor that increases the risk of functional decline by $35 \%$ during the hospital stay $[1,4]$. Severe respiratory infections, fractures and pressure wounds are other common complications reported among the elderly as a result of hospitalization [5,6]. Additionally, the transfer to the hospital, a new and unknown environment, creates an inconvenience for the elderly patient [7].

Acute respiratory infections are the most common causes for referring elderly patients from nursing homes to hospitals [8]. The above factors contribute to a higher mortality rate and increase the chance for other severe consequences, like pressure wounds, among the hospitalized, when compared with non-hospitalized elderly patients who are taken care of at the nursing home [4].

Nursing home related variables, like private ownership, belonging to a network of NHs, poor environmental conditions, a lack of patient privacy and poor satisfaction among the elderly and staff, are related to higher rates of elderly patient referral from NHs to hospitals $[9,10]$.

In a study conducted by Menec (2008), patient related variables like younger age, general deterioration and a need for additional assistance in Activities of Daily Living (A.D.L.) contribute to higher rates of hospitalizations. In this study $41 \%$ of elderly patients were hospitalized at least once in general hospitals during the six months before they died [11].

The decision of nursing home staff to refer patients to a general hospital is difficult. Lacking clear instructions from the Ministry of Health, the staff might feel obligated to refer patients to hospitals despite potentially severe consequences [7].

About half of elderly patients' referrals from NHs to hospitals are not justified and occur regardless of preliminary instructions [12].

Medical managers and head nurses have different perceptions with respect to the factors that affect patients' referral to general hospitals. Commonly perceived factors include the availability of physicians, their payment level and the preferences of the patients' families. These differences in perception might impose difficulties on conducting effective interventions directed at minimizing referral rates. Improving communication and reaching a consensus among the staff regarding patient referrals to general hospitals are important components. Furthermore, preliminary instructions and treatment according to the patients' needs will minimize referral rates [13].

Elderly patients in NHs receive 24 hour availability of nursing staff and caregivers, as well as the presence of medical and paramedical staff. However, there is still a widespread phenomenon of referring elderly patients in NHs to general hospitals for medical care. Therefore, it is important to identify the factors correlated with elderly referral from NHs to general hospitals. In this study, we examined the factors related to elderly referral rates from NHs to general hospitals in the Haifa sub-district, as well as the correlation between referral rates and mortality rates in these NHs, from November 2006 to October 2007, in order to determine the needs for an intervention policy to reduce the referring of elderly patients to general hospitals. Such a study has not been conducted yet in Israel.

\section{Methods}

The Haifa sub-district has a total population of approximately 550,000 residents, $16 \%$ of whom are above 64 years old. Thirty-three licensed $\mathrm{NHs}$ which contain a total of about 2,500 beds are located within the Haifa subdistrict. Thirty-two of the NHs are connected to the Haifa District Health Office by the SAP ${ }^{\circ}$ (Systems, Applications, and Products in Data Processing) software. The medical managers and the head nurses (senior staff) of the above mentioned $32 \mathrm{NHs}$ were interviewed using a structured questionnaire that included the following variables: [1] qualification and availability of staff in the NHs; [2] referring professionals; and [3] knowledge and attitude of senior staff members on the topic of elderly referral.

Data about the NHs was collected using the SAP ${ }^{\circ}$ software in the Haifa District Health Office, (HDHO). Collection of data occurred between 1/11/2006 and 31/10/2007 and included several variables such as the number of licensed beds in the NHs, the number of elderly referrals to general hospitals for each $\mathrm{NH}$, the number of hospital admissions, the duration of the admission in days, and the total number of deaths for each $\mathrm{NH}$. The data referred only to elderlies whose $\mathrm{NH}$ stay was financed by the Ministry of Health, (MOH), (locally known as "codes"), as computerized data was readily available for this group. Later in the study, the NHs were divided into two groups: larger NHs with greater than 50 licensed beds, and smaller NHs with fewer than 50 licensed beds. This was done in order to examine the size of a $\mathrm{NH}$ as an independent variable that may influence the referral rate. The senior staff of each NH was interviewed between May and August 2009. They were asked to consider the average referral rate in their $\mathrm{NH}$ in comparison with the average referral rate in the Haifa sub-district. The referral rate, which was the main dependent variable, was defined as the number of patient referrals divided by the total number of financed elderly throughout a single year. We examined the relationship between the referral rate and the independent variables: the medical managers' availability (hours per week), medical managers' specialty, geriatric nurse training, nurses' qualification, referral form details (whether directly by the physician or indirectly through the nurse), $\mathrm{NH}$ size, and the professional knowledge of the senior staff. The professional knowledge of the senior staff was examined using four theoretical scenarios about the 
medical status of elderly patients. The mortality rate was defined as the number of deaths divided by the total number of financed elderly throughout a single year.

Statistical analysis, using SPSS software, included univariate and multivariate analysis. Referral rates were investigated using variance analysis (ANOVA) to determine whether the mean referral values, observed in different groups of NHs, differ by the above-mentioned categorical variables. The Spearman nonparametric correlation test was performed to determine the correlation between the mortality rate and the referral rate. A value of $\mathrm{P}<0.05$ was considered statistically significant.

\section{Results}

The study population included $32 \mathrm{NHs}$ out of the $33 \mathrm{li}$ censed NHs in the Haifa sub-district. These NHs constituted a convenient sample due to their connection with $\mathrm{SAP}^{\circ}$ software and available computerized data. One $\mathrm{NH}$ was not included due to a lack of connection with this software. Out of the $32 \mathrm{NHs}, 17$ were considered big and 15 were considered small. The referral rate distribution and main characteristics of $\mathrm{NHs}$ are demonstrated in Table 1.

The availability of the medical managers ranged from 9 to 12 hours per week in fifteen of the NHs (47\%), 24 hours per week in six of the NHs (19\%) and one hour per week in one NH. Nineteen (59\%) of the medical managers were general practitioners and seven physicians were specialists in geriatrics. In $18 \mathrm{NHs}$ (56\%), more than 50\% of the nurses were registered nurses. In 19 NHs (59\%) qualified geriatric-trained nurses were employed. In all $\mathrm{NHs}$, a registered nurse was available during the morning shift, in $81.3 \%$ of the NHs, a registered nurse was available during the afternoon shift, and in $50 \%$ of the NHs, a registered nurse was available during the night shift. Only seven NHs have permission to conduct intravenous treatment. The senior staff of 17 of the NHs had a success rate of $75 \%$ or more in the knowledge exam (had a correct answer for at least 3 out of the 4 knowledge-oriented medical scenarios).

The referral rate ranged between 18 and 222 per 100 financed elderly in a single year, with a median of 60 . A wide variation of referral rates was found among NHs. No statistical difference was detected between the referral rates of big and small NHs, $\left(\mathrm{Chi}^{2}=0.08, \mathrm{P}\right.$ value $=$ 0.783). Therefore, further analysis was performed for all NHs.

In twenty-five NHs (78\%) the physician was available, examined the patient, and referred him directly. Conversely, in seven NHs (22\%) the physician was not available and the nurse consulted with him by phone. The referral in this case was done indirectly by sending a referral form by fax.
Table 1 Characteristics of Nursing Homes (NHs) by number of beds category (small/large) in Haifa sub district in 2006-2007 (standard deviation and percentages in parenthesis)

\begin{tabular}{|c|c|c|c|}
\hline & $\begin{array}{l}\text { Small NHs* } \\
\quad N=15\end{array}$ & $\begin{array}{l}\text { Large } \mathrm{NHs}^{* *} \\
\qquad \mathrm{~N}=17\end{array}$ & $P$ value \\
\hline Specialized medical manager (\%) & $6(40.0 \%)$ & $7(41.2 \%)$ & .615 \\
\hline \multicolumn{4}{|l|}{ Physician availability per day } \\
\hline Up to 8 hours & $10(66.7 \%)$ & $5(29.4 \%)$ & \multirow{3}{*}{.102} \\
\hline 9-12 hours & $2(13.3 \%)$ & $6(35.3 \%)$ & \\
\hline 13 and more hours & $3(20.0 \%)$ & $6(35.3 \%)$ & \\
\hline \multicolumn{4}{|l|}{$\begin{array}{l}\text { Registered nurse availability } \\
\text { per shift (\%) }\end{array}$} \\
\hline Morning & $4(26.7 \%)$ & $2(11.8 \%)$ & \multirow{3}{*}{.550} \\
\hline Morning and afternoon & $4(26.7 \%)$ & $6(35.3 \%)$ & \\
\hline Morning, afternoon and night & $7(46.7 \%)$ & $9(52.9 \%)$ & \\
\hline \multicolumn{4}{|l|}{ Referral form (\%) } \\
\hline Direct & $10(66.7 \%)$ & $15(88.2 \%)$ & \multirow{2}{*}{.149} \\
\hline Indirect & $5(33.3 \%)$ & $2(11.8 \%)$ & \\
\hline $\begin{array}{l}\text { Average referral rate per } 100 \\
\text { financed beds }(\mathrm{SD})^{* * *}\end{array}$ & $\begin{array}{c}69.1 \\
(S D=54.0)\end{array}$ & $\begin{array}{c}63.7 \\
(\mathrm{SD}=28.1)\end{array}$ & .722 \\
\hline $\begin{array}{l}\text { Average annual mortality rate } \\
\text { per } 100 \text { financed beds (SD) }\end{array}$ & $\begin{array}{c}35.3 \\
(S D=19.2)\end{array}$ & $\begin{array}{c}31.3 \\
(S D=15.8)\end{array}$ & .525 \\
\hline $\begin{array}{l}\text { Average length of stay in days } \\
\text { in general hospitals (SD) }\end{array}$ & $7.2(\mathrm{SD}=3.3)$ & $6.4(S D=1.5)$ & .400 \\
\hline
\end{tabular}

Note: *Small NHs (<=49 licensed beds): were included 506 beds with 162 referrals to general hospitals in study period. ${ }^{* *}$ Large $N H s(>=50$ licensed beds): were included 1829 beds with 887 referrals to general hospitals in study period. ${ }^{* *}$ Financed by Ministry of Health.

Lower referral rates were observed when direct referrals were made by physician than when indirect referrals were made by a registered nurse. This difference was significant, $\mathrm{F}=7.461, \mathrm{p} \leq 0.01$ (Table 2).

Lower referral rates were also observed to be dependent upon the physicians' specialization and availability. However this relationship was not significant, $\mathrm{F}=1.641$, $\mathrm{p}=0.210$ and $\mathrm{F}=0.787, \mathrm{p}=0.465$, respectively.

Analysis of variance (ANOVA) showed no significant relationship between referral rates and the other variables including physician availability and specialty, registered nurse availability and senior staff knowledge (Table 2).

In multivariate analysis, the referral form variable remained significant and demonstrated the lowest rates in case of direct referral to general hospitals by physicians $(\mathrm{t}=-2.128, \mathrm{P}=0.043)$.

Multivariate analysis showed no significant relationship between referral rates and the other variables, including senior staff knowledge, physician availability and specialty, and nurse availability, qualification and training.

Eighty-one percent of the medical managers in NHs where the referral rates were lower than the median reported that the referral rates of their $\mathrm{NH}$, in their opinion, were low. On the other hand, $44 \%$ of the medical 


\begin{tabular}{|c|c|c|c|c|}
\hline Variable & $\mathbf{N}$ & $\begin{array}{c}\text { Average } \\
\text { referral rate }\end{array}$ & $F(d f)$ & $P$ value \\
\hline \multicolumn{5}{|l|}{ Specialized medical manager: } \\
\hline General & 19 & 73.9 & 1.641 & \multirow{2}{*}{0.210} \\
\hline Specialized & 13 & 55 & (1) & \\
\hline \multicolumn{5}{|l|}{ Physician availability per day } \\
\hline Up to 8 hours & 15 & 75.7 & 0.787 & \multirow{3}{*}{0.465} \\
\hline $9-12$ hours & 8 & 61.6 & (2) & \\
\hline 13 and more hours & 9 & 54.6 & & \\
\hline \multicolumn{5}{|l|}{ Registered nurse availability per shift } \\
\hline Morning & 6 & 72.3 & 0.106 & \multirow{3}{*}{0.900} \\
\hline Morning and afternoon & 10 & 62.2 & (2) & \\
\hline Morning, afternoon and night & 16 & 66.5 & & \\
\hline \multicolumn{5}{|l|}{ Referral form* } \\
\hline Direct & 25 & 56.6 & 7.461 & \multirow{2}{*}{0.010} \\
\hline Indirect & 7 & 100.7 & (1) & \\
\hline \multicolumn{5}{|l|}{ Knowledge among medical managers } \\
\hline No correct answers & 1 & 98 & & \\
\hline One answer of the four correct & 4 & 82.7 & 0.333 & \\
\hline Two answers of the four correct & 9 & 61.1 & (4) & 0.854 \\
\hline Three answers of the four correct & 15 & 63.9 & & \\
\hline All answers correct & 3 & 60.7 & & \\
\hline
\end{tabular}

*Significant.

managers in NHs where the referral rates were higher than the median reported that the referral rates of their $\mathrm{NH}$, in their opinion, were high. The relationship between the attitude of medical managers and the referral rates in their NH's was borderline significant, $\mathrm{Chi}^{2}=$ 4.886 , $\mathrm{P}$ value $=0.087$. No significant relationship between referral rates and mortality rates was found, Pearson Correlation $=-0.025$, $\mathrm{P}$ value $=0.892$.

\section{Conclusions}

In this study we examined the relationship between elderly referral rates and a mix of human resources, staff knowledge and other characteristics of NHs. The study population included $32 \mathrm{NHs}$ out of the 33 licensed NHs in the Haifa sub-district. These NHs constituted a convenient sample due to their connection with $\mathrm{SAP}^{\circ}$ software and available computerized data. One $\mathrm{NH}$ was not included due to a lack of connection with this software. The data, included in this study, referred only to elderlies whose $\mathrm{NH}$ stay was financed by the Ministry of Health, (MOH), (locally known as "codes"), as computerized data was readily available for this group. Including data about elderly patients whose hospitalization was not financed by the $\mathrm{MOH}$, proved difficult as the data, relevant to them, was not computerized. This is a good topic to be included in a future study.

A significant decrease in referral rates was observed when the physician was present in the $\mathrm{NHs}$ and referred the patient directly. In seven NHs, the physician was not available and the nurse consulted with him by phone. The patient referral in this case was done indirectly by sending a referral form by fax. In these NHs, higher referral rates were observed. Lower referral rates were also observed to be dependent upon the physicians' specialization and availability. However this relationship was not significant. Higher referral rates may be attributed to the fact that some NHs did not offer malpractice insurance for employed physicians. This, in turn, may have led the physicians to prefer referring patients to a general hospital to taking responsibility for an in-house treatment. This hypothesis was not examined in this study. Since 2008, NHs listed by the $\mathrm{MOH}$ as approved for financed hospitalization after going through the bidding process, offer general insurance to all employed physicians.

In Israel, NHs are paid for 2 weeks after elderly referral and hospitalization in a general hospital, even though they are allowed to admit another elderly patient during this time, and to be paid for them as well. This might render the decision to refer a patient to a general hospital fairly "easy", considering the potential profit of such an action. This hypothesis was not examined in this study.

No significant relationship was found between the referral rates and the percentage of qualified nurses, geriatric training among nurses and permission to conduct intravenous treatment in the NHs. The non-significant relationship demonstrated between the referral rates and those variables may be attributed to the small sample size of NHs included in the study.

In published studies, referral rates are influenced by the characteristics of $\mathrm{NHs}$ and the quality of service they provide. [3,9]. Availability of qualified nurses in nursing homes was found to be directly related to elderly referral rates and due to health conditions like diabetes mellitus, COPD, dehydration, pneumonia and urinary tract infections [14]. Increased nursing staff skills and interventions were related to a decrease in referral rates [2]. Availability of qualified nurses, permission to conduct intravenous treatments, and training interventions among medical and nursing staff were related to a decrease in referral rates $[10,14]$. Lack of qualified nurses in NHs was related to higher referral rates [15]. Permission to conduct intravenous treatment in NHs has led to a decrease in elderly referral rates by $40 \%-50 \%$ [5].

In our study no significant relationship was found between referral rates and mortality rates. This finding may suggest that higher referral rates do not necessarily lead to higher mortality rates nor do they protect the patients from death. 


\section{Limitations}

1. Our study is population-based and included a convenient small sample of all the NHs in the Haifa sub-district (32 NHs). This might explain the absence of a significant relationship between referral rates and most of the independent variables. Moreover, because of the small sample size, the findings may be biased. Expansion of the sample size of the NHs is required for future studies.

2. No data regarding the medical causes for elderly referral was collected.

3. The data about mortality rates was population-based. No individual follow up of a hospitalized patient was conducted. Further individual study is required in order to determine the relationship between referral rates and mortality rates.

\section{Recommendations}

1. An additional study, including data about the elderlies whose $\mathrm{NH}$ stay is not financed by the $\mathrm{MOH}$, should be considered.

2. Further quantitative and epidemiologic studies should be conducted in order more fully and reliably create guidelines for policy recommendations.

3. The MOH should issue criteria for the referral of patients from a nursing home to a general hospital.

4. $\mathrm{MOH}$ should increase the presence of physicians in the NHs, especially when the need to refer a patient arises. $\mathrm{MOH}$ should require the physician to be present in cases where a referral is to be issued.

5. $\mathrm{MOH}$ should consider the option of encouraging referrals to geriatric emergency rooms.

6. Similar studies should be conducted among other $\mathrm{NHs}$ in other districts. Further studies are required to evaluate the intervention.

\section{Competing interests}

The authors declare that they have no competing interests.

\section{Authors' contribution}

SW and GK initiated the study and took the lead in its planning and implementation. SH took the lead in writing the article. All of the authors (SH, SW, GK, JD and SR) participated in the study's planning and implementation, as well as the preparation of the manuscript. All of the authors have reviewed and approved the final manuscript.

\section{Author's information}

Sonia Habib is a public health specialist, Deputy District Health Officer in Haifa Health Office and acting Head of Haifa Sub District health office and a teacher at the Public Health School, Haifa University. Shir Wagman is Deputy Head Nurse, Public Health Services, Ministry of Health. Genady Kagan is the District Geratrician, in Haifa District of Health Office. Jonathan Dubnov is a public health specialist, Deputy District Health Officer in Haifa Health Officeand a lecturer at the Public Health School, Haifa University. Shmuel Rishpon is a public health specialist, Haifa District Health Officer, an Associate professor at the Public Health School, Haifa University and Head of the Advisory Committee on Infectious Diseases and Immunizations.

\section{Acknowledgment}

The authors greatly appreciate Prof. Avi Israeli for his contribution and helpful comments and support.

\section{Author details}

${ }^{1}$ Ministry of Health, Jerusalem, Israel. ${ }^{2}$ Haifa District Health Office, Ministry of Health, Haifa, Israel. ${ }^{3}$ Faculty of Welfare and Health Sciences, School of Public Health, University of Haifa, Haifa, Israel.

Received: 9 May 2013 Accepted: 14 November 2013

Published: 23 January 2014

\section{References}

1. Halter JB, Ouslander JG, Tinetti ME, Sudenski S, Hihg KP, Asthana S: Chapter 15: health care system and chapter 16: transition. In Hazzard's Geriatric Medicine and Gerontology. 6th edition. USA: Mc Graw- Hill Companies, Inc; 2009.

2. Konetzka RT, Spector W, Limcangco MR: Reducing Hospitalization from Long-Term Care Settings. Med Care Res Rev 2008, 65:40-65.

3. Grabowski DC, Stweart KA, Broderick SM, Coots LA: Predictors of nursing home hospitalization. A review of the literature. Med Care Res Rev 2008, 65:3-39.

4. Boockvar KS, Gruber-Baldini AL, Burton L, Zimmerman S, May C, Magaziner $\mathrm{J}$ : Outcomes of infection in nursing home residents with and without early hospital transfer. J Am Geriatr Soc 2005, 53:590-596.

5. Barker WH, Zimmer JG, Hall WJ, Ruff BC, Freundlich CB: Rates, patterns, causes, and costs of hospitalization of nursing home residents: a population- based study. Am J Public Health 1994, 84:1615-1620.

6. Baumgarten M, Margolis DJ, Russell AL, Kagan SH, Baumgarten M, Margolis DJ, Russell AL, Kagan SH, Lowe RA, Kinosian B: Pressure ulcers among elderly patient early in the hospital stay. J Gerontol 2005, 61:749-754.

7. Travis SS, Loving G, McLanahan L, Bernard M: Hospitalization patterns and palliation in the last year of life among residents in long-term care. Gerontologist 2001, 41:153-160.

8. Chan Carusone SB, Walter SD, Brazil K, Loeb MB: Pneumonia and lower respiratory infections in nursing home residents: predictors of hospitalization and mortality. J Am Geriatr Soc 2007, 55:414-419.

9. Zimmerman S, Gruber-Baldini AL, Hebel JR, Sloan PD, Magaziner J: Nursing home facility risk factors for infection and hospitalization: importance of registered nurse turnover, administration, and social factors. J Am Geriatr Soc 2008, 50:1987-1995.

10. Carter MW, Porel FW: Variations in hospitalization rates among nursing home residents: the role of facility and market attributes. Gerontolog 2002, 43:175-191.

11. Menec VH, Nowicki S, Blandford A, Veselyuk D: Hospitalizations at the End of life among long-term care residents. J Gerontol 2008, 64A:395-402.

12. Saliba D, Kinaton R, Buchanan J, Bell R, Wana M, Lee M, Herbst M, Lee D, Sur D, Rubenstein I: Appropriateness of the decision to transfer nursing facility residents to the hospital. J Am Geriatr Soc 2000, 4:154-163.

13. Ackerman RJ, Kemle KA: Death in a nursing home with active medical management. Ann Long Term Care 1999, 7:313-319.

14. Intrator O, Zinn J, Mor M: Nursing home characteristics and potentially preventable hospitalizations of long- stay residents. J Am Geriatr Soc 2004, 52:1730-1736.

15. Rector TS, Spector D, Shaffer TJ, Finch MD: Pneumonia in nursing home residents: factors associated with in-home care of EverCare enrollees. J Am Geriatr Soc 2005, 53:472-477.

doi:10.1186/2045-4015-3-2

Cite this article as: Wagman et al:: Variables correlated with elderly referral from nursing homes to general hospitals. Israel Journal of Health Policy Research 2014 3:2 